\title{
EL CONCEPTO DE ARBITRARIEDAD DEL ARTÍCULO 16 A) DE LA LEY DE CONSUMO: ANÁLISIS DE LOS CRITERIOS JUDICIALES QUE EXAMINA LA CLÁUSULA DE MODIFICACIÓN UNILATERAL
}

\author{
THE CONCEPT OF ARBITRARINESS OF ARTICLE \\ 16 (A) OF THE CONSUMER LAW: ANALYSIS OF THE \\ JUDICIAL CRITERIA THAT EXAMINES THE UNILATERAL \\ AMENDMENT CLAUSE
}

FRANCISCA BARRIENTOS CAMUS* Prof. de Derecho Civil Universidad Diego Portales Santiago - Chile

\section{RESUMEN}

Este artículo tiene por objetivo identificar los criterios judiciales de la cláusula de modificación unilateral en los contratos por adhesión celebrados con consumidores. Se ofrece un estudio de sentencias que examinan los mercados de servicios de televisión por cable, educacionales, internet, telefónicos, salud, tiempos compartidos, entretenimiento, aéreos, deportivos y funerarios.

Palabras clave: Derecho del consumidor, cláusulas abusivas, modificación unilateral.

* Licenciada en Ciencias Jurídicas, abogada. Magíster en Derecho Privado y Doctora en Derecho, Universidad de los Andes, Chile. Correo electrónico francisca.barrientos@mail.udp.cl. Este artículo forma parte del proyecto FONDECYT de iniciación $\mathrm{N}^{\mathrm{o}}$ 11140516, del cual la autora es responsable. Artículo recibido el 17 de agosto de 2017 y aceptado para su publicación el 13 de noviembre de 2017. 


\section{ABSTRACT}

This article aims to identify the judicial criterions of the unilateral modification clause in adhesion contracts concluded with consumers. This paper offers a study of judgments examining the markets for cable television, educational, internet, telephone, health, timeshare, entertainment, air, sports and funeral services.

Keywords: Consumer law, unfair contracts terms, unilateral modification clause.

\section{INTRODUCCIÓN. DESCRIPCIÓN DEL PROBLEMA DE ESTUDIO}

Uno de los fallos más importantes en el ámbito del consumidor, Servicio Nacional del Consumidor ${ }^{1}$ con CENCOSUD ${ }^{2}$ declaró la ineficacia de las cláusulas contenidas en los numerales $9^{\circ}$ y $16^{\circ}$ del contrato y del reglamento, ${ }^{3}$ que permitían el aumento de la comisión por mantención del servicio en más del $100 \%$ del valor originalmente pactado, por estimar que se infringió el artículo 16 letra a) de la Ley sobre protección de los derechos de los consumidores $\mathrm{N}^{\mathrm{o}}$ 19.496 de $1997 .{ }^{4}$

Sin embargo, hay que señalar que en ninguna parte del mentado fallo se describe por qué la cláusula predispuesta por la empresa fue calificada como arbitraria. Sólo existen referencias al silencio y su distinción con la manifestación tácita de la voluntad, ${ }^{5}$ que se encuentran íntimamente ligados. Por eso Momberg

${ }^{1}$ En adelante, SERNAC.

${ }^{2}$ Corte Suprema, 24 de abril de 2013, Rol No 12.355-11.

${ }^{3}$ La clausula establecía que "Cualquier cambio de las condiciones de uso y privilegios de la tarjeta deberá ser informado por escrito al usuario, entendiéndose que éste acepta si mantiene o utiliza la tarjeta después de 30 días de expedida la comunicación respectiva. Si el usuario decidiere no aceptar las variaciones podrá poner término de inmediato al contrato mediante el aviso a la empresa y haciéndole entrega material de las tarjetas que hubiere recibido".

${ }^{4}$ En adelante, ley o LPDC.

${ }^{5}$ Sobre este tema ver, entre otros, PINOCHET OlaVe, Ruperto, "La voluntad y el silencio en los contratos de adhesión el que calla no otorga. Una revisión a propósito de la sentencia de la Excma. Corte Suprema de 24 de abril de 2013 recaída en el caso Sernac con Cencosud", en: Turner, S. y Varas, J.A. (coords.), Estudios de Derecho Civil IX, Legal Publishing-Thomson Reuters, Santiago, 2014, pp. 427-442; Pizarro Wilson, Carlos, "La ley debe regular los actos que valgan aceptación de ofertas de modificación", en: Barrientos, F. (coord.), Condiciones generales de la contratación y cláusulas abusivas, Cuadernos de Análisis Jurídicos. Colección de derecho privado VIII, Ediciones Universidad Diego Portales, Santiago, 2014, pp. 19-28; Barrientos Camus, Francisca, "Una mirada al silencio y 
sostiene "...el no conceder al consumidor la alternativa de mantener vigente el contrato en sus términos originales, supone el hecho de dejar al arbitrio del predisponente la modificación del contrato...". 6

Hasta el momento no se ha reparado sobre el concepto de arbitrariedad que regula el artículo 16 letra g) de la LPDC. En realidad, los autores han centrado su atención en la descripción de la cláusula, como Tapia y Valdivia. ${ }^{7}$ Momberg $^{8}$ describe en los requisitos, al examinar las formas válidas de esta estipulación; mientras que Pizarro y Petit, ${ }^{9}$ los cuestionan. Con todo, Isler ${ }^{10}$ caracteriza alguna de estas cláusulas, según si alteran la prestación o el precio.

Y esto es importante, pues existen más de treinta sentencias judiciales ${ }^{11}$ en el medio nacional, que muestran la presencia de una cláusula de modificación unilateral predispuesta por el proveedor.

Con estos antecedentes parece necesario identificar la forma en que los jueces han interpretado la expresión "arbitrariedad" consagrada en el artículo 16 a) de la ley.

Así, el objetivo de esta presentación es sencillo, se trata de examinar y

la aceptación en los contratos por adhesión con consumidores a partir del caso CENCOSUD”, en: Barrientos, F. (coord.), Condiciones generales de la contratación y cláusulas abusivas, Cuadernos de Análisis Jurídicos. Colección de derecho privado VIII, Ediciones Universidad Diego Portales, Santiago, 2014, pp. 29-48.

6 Momberg Uribe, Rodrigo, "Primera Sala de la Corte Suprema, 24 de abril de 2013, Rol 12.355-11", Revista chilena de Derecho Privado, 2013, No 20, pp. 245-253. En la misma línea, BARRIENTos CAmus, Francisca, "Silencio y aceptación tácita. Aumento unilateral. Prescripción", Revista chilena de Derecho Privado, 2013, No 20, p. 256.

7 Tapia Rodríguez, Mauricio; Valdivia Olivares, José Miguel, Contrato por adhesión. Ley N 19.496, Editorial Jurídica de Chile, Santiago, 2002, pp. 93-98.

${ }^{8}$ Momberg Uribe, Rodrigo, "Las cláusulas de modificación unilateral en los contratos de consumo", en: Barrientos, F. (coord.), Condiciones generales de la contratación y cláusulas abusivas, Cuadernos de Análisis Jurídicos. Colección de derecho privado VIII, Ediciones Universidad Diego Portales, Santiago, 2014, pp. 178-186.

9 Pizarro Wilson, Carlos; Petit Pino, Jean, "Comentarios al artículo 16 a”, en: De la Maza, Í. y Pizarro, C. (directores); Barrientos, F. (coord.), La protección de los derechos de los consumidores, Editorial Thomson Reuters, Santiago, 2013, p. 308.

${ }^{10}$ IsLER Soto, Erika, "La causal de abusividad establecida en el artículo 16 letra a) de la LPDC", en: Barrientos, F. (coord.), Condiciones generales de la contratación y cláusulas abusivas, Cuadernos de Análisis Jurídicos. Colección de derecho privado VIII, Ediciones Universidad Diego Portales, Santiago, 2014, pp. 152-162.

${ }^{11}$ Se han buscado fallos en los portales de sentencias más conocidas del país, como Legal Publishing y Microjuris. Junto con eso, se ha tenido a la vista el registro de sentencias del Servicio Nacional del Consumidor. La búsqueda ha sido por artículo y por las voces "modificación unilateral", "buena fe", "precio", "cláusulas abusivas". Estos portales y registros han arrojado un total de 72 sentencias. La mayoría de ellas se encuentra publicada en el portal de la Academia de Derecho y Consumo: www. derechoyconsumo.udp.cl, gracias a los aportes del proyecto FONDECYT No 11140516. 
ponderar la mirada judicial de la cláusula de modificación unilateral predispuesta por el proveedor. Entonces, como se trata de una descripción de la praxis judicial, sólo se formularán algunas referencias a la dogmática nacional y comparada.

\section{LAMIRADA DELOSJUECESSOBRE LACLÁUSULADEMODIFICACIÓN UNILATERAL}

Para comenzar este capítulo conviene, en primer lugar, examinar la norma que regula la cláusula de modificación unilateral del contrato. Luego, se estudiarán los criterios judiciales que la delimitan, distinguiendo entre las alteraciones a la prestación y las variaciones al precio pagado por el consumidor.

\section{Las facultades arbitrarias del proveedor}

El artículo 16 letra a) de la ley dispone que: "No producirán efecto alguno en los contratos de adhesión las cláusulas o estipulaciones que: Otorguen a una de las partes la facultad de dejar sin efecto o modificar a su solo arbitrio el contrato o de suspender unilateralmente su ejecución, salvo cuando ella se conceda al comprador en las modalidades de venta por correo, a domicilio, por muestrario, usando medios audiovisuales, u otras análogas, y sin perjuicio de las excepciones que las leyes contemplen".

Se ha explicado que la estipulación que autoriza el aumento unilateral o arbitrario del proveedor debería ser considerado abusivo o ilegítimo porque deja a discreción del proveedor cuándo y cómo ejecutar la prestación. Con ello, el consumidor queda en una situación de incerteza respecto del cumplimiento cabal de la obligación del proveedor. ${ }^{12}$

Sin perjuicio de lo anterior, también se considera que la cláusula puede ser lícita si cumple de forma excepcional ciertos requisitos. En efecto, MoMBERG ${ }^{13}$ explica que si la facultad de modificación se basa en parámetros objetivos y el consumidor queda esencialmente indemne de la variación del contrato, podría permitirse. En el mismo sentido, consideran esos parámetros objetivos De la

\footnotetext{
${ }^{12}$ Pizarro y Petit, cit. (n. 9), p. 306.

${ }^{13}$ Momberg, cit. (n. 8), pp. 179-186.
} 


\section{Maza, ${ }^{14}$ Pizarro y Petit, ${ }^{15}$ Barrientos, ${ }^{16}$ Tapia,,${ }^{17}$ Caprile ${ }^{18}$ y Rozas. ${ }^{19}$}

Entonces, esta norma le entrega al Juez la facultad de decidir la eficacia o ineficacia de una cláusula predispuesta por el proveedor. Detrás de esto, de alguna forma, se aprecia cómo el derecho de contratos va dejando de lado el "enfoque del bilateralismo" al preferir el "enfoque de unilateralismo". ${ }^{20}$

Dicho eso, ahora corresponde decir que se observará la praxis judicial, para examinar en qué casos los jueces han declarado abusivas algunas cláusulas de modificación unilateral y en qué otros casos se han declarado lícitas.

Por eso, siguiendo una sistemática que examina las circunstancias típicas según el sector negocial, ${ }^{21}$ como criterio objetivo ${ }^{22}$ y aceptado $^{23}$ de

${ }^{14}$ De la MAZA, Íñigo, “¿Llegar y llevar? Una mirada al crédito de las casas comerciales”, Revista de Derecho (Valdivia), 2007, Vol. XX No 1, pp. 70-71.

${ }^{15}$ Pizarro y Petit, cit. (n. 9), p. 307.

${ }^{16}$ Barrientos Camus, Francisca, "La modificación unilateral en los contratos de salud y televisión por cable. Criterios judiciales", en: Departamento de Derecho Privado Universidad de Concepción (editores); Barría, M. (coord.), Estudios de derecho civil XI, Thomson Reuters, Santiago, 2015, p. 465.

${ }^{17}$ TAPIA explicita las condiciones formales del ejercicio de la facultad de modificar unilateralmente el contrato. Primero, tiene que haber un envío que cumpla con las formalidades que exige el artículo 17 LPDC. Segundo, debe estar redactada de forma clara y legible, conforme lo ordena el artículo 32, o en términos simples del artículo $17 \mathrm{~B}$, siempre que contenga motivaciones plausibles y objetivas que la justifican, así como los derechos que se le concedan al consumidor. Y, tercero, debe ser enviada con un plazo de antelación, que en materia financiera se traducen en 30 días hábiles, en TAPIA RodríGUEZ, Mauricio "Silencio y aceptación del consumidor", en: Turner, S.; Varas, J.A. (coords.), Estudios de Derecho Civil IX, Legal Publishing- Thomson Reuters, Santiago, 2014, pp. 450-451.

${ }^{18}$ CAPrile Biermann, Bruno, "El desistimiento unilateral o renuncia: una especial forma de extinción de los contratos", en: Figueroa, G.; Barros, E.; Tapia, M. (coords.), Estudios de Derecho Civil VI, Editorial Abeledo Perrot Legal Publishing, Santiago, 2011, p. 274.

${ }^{19}$ Rozas Zambrano, Marco, "Posibilidad de dejar sin efecto el contrato en la ley del consumidor", en: Barrientos F. (coord.), Condiciones generales de la contratación y cláusulas abusivas, Cuadernos de Análisis Jurídicos. Colección de derecho privado VIII, Ediciones Universidad Diego Portales, Santiago, 2014, pp. 254-258.

${ }^{20}$ Ríos examina estos enfoques a través de manifestaciones del unilateralismo en el derecho de contratos en una serie de instituciones: la formación del contrato, la modificación de los contratos y la terminación del contrato, en Ríos LabBé, Sebastián, "El papel del unilateralismo en el derecho de los contratos", en: Schopf, A.; Marín, J.C. (editores), Lo público y lo privado en el derecho, Thomson Reuters, Santiago, 2017, p. 643.

${ }^{21}$ Durany Pinch, Salvador, “Artículos 5 y 7”, en: Menéndez, A.; Díez Picazo, L. (dirs.); Alfaro ÁguilaReal, J. (coord.), Comentarios a la Ley sobre Condiciones Generales de la Contratación, Civitas, Madrid, 2002, p. 319.

${ }^{22}$ Cfr. DíEz PicAzo señala que el examen de la abusividad debe tomar en consideración una mirada conjunta del contrato, en Diez Picazo, Luis, Fundamentos de Derecho Civil Patrimonial I. Introducción a la teoría del contrato, Thomson Reuters, Madrid, 2007, 6ta edic., p. 443.

${ }^{23}$ En Chile no existen normas. Por eso, corresponde citar el artículo $4 \mathrm{~N}^{\circ} 1$ de la Directiva 93/13/ CEE del Consejo, de 5 de abril de 1993, sobre las cláusulas abusivas en los contratos celebrados con 
interpretación de los contratos por adhesión, he dividido el estudio de las sentencias que analizan estas materias por mercado. De modo que se ofrece un estudio de la situación judicial de las cláusulas insertas en el ámbito de los canales televisivos, servicios educacionales, servicios de internet, servicios telefónicos, servicios de salud, tiempos compartidos, entretenimiento, servicios de transporte aéreo, deportivos y funerarios. Excluyo los servicios financieros porque existen reglas especiales para ellos, ${ }^{24}$ tras la incorporación de la ley $\mathrm{N}^{\mathrm{o}}$ 20.550 de 2011 a la LPDC conocida como "Sernac financiero".

Junto con lo anterior, corresponde señalar que se han categorizado las sentencias que discurren sobre la modificación predispuesta por el proveedor en dos formas típicas. Primero, la que intenta alterar la prestación. Segundo, la que intenta alterar el precio por los servicios.

\section{Modificación unilateral relacionada con la prestación}

Para iniciar el análisis, en este apartado estudiaré (a) las alteraciones parciales y (b) las alteraciones totales de la prestación.

\section{a. Alteraciones parciales de la prestación}

En este acápite se examinarán los cambios de canales en el ámbito de la televisión por cable y algunas jornadas de los establecimientos educacionales:

i. Alteraciones en la parrilla programática de canales televisivos. En el ámbito de la televisión por cable se retiró de la grilla programática el canal TYC (Torneos y Competencia) sustituyéndolo por el canal CDF Básico (Canal del Fútbol), que luego fue incorporado a una programación especial premium, que se contrataba por separado pagando un precio adicional.

Los hechos descritos fueron conocidos en dos oportunidades, pero los

consumidores, que disciplina ciertos criterios. La disposición señala “... el carácter abusivo de una cláusula contractual se apreciará teniendo en cuenta la naturaleza de los bienes o servicios que sean objeto del contrato y considerando, en el momento de la celebración del mismo, todas las circunstancias que concurran en su celebración, así como todas las demás cláusulas del contrato, o de otro contrato del que dependa".

${ }^{24} \mathrm{La}$ disposición se encuentra establecida en el artículo $17 \mathrm{~B}$ inciso final LPDC en los siguientes términos: "Los contratos que consideren cargos, comisiones, costos o tarifas por uso, mantención u otros fines deberán especificar claramente sus montos, periodicidad y mecanismos de reajuste. Estos últimos deberán basarse siempre en condiciones objetivas que no dependan del solo criterio del proveedor y que sean directamente verificables por el consumidor. De cualquier forma, los valores aplicables deberán ser comunicados al consumidor con treinta días hábiles de anticipación, al menos, respecto de su entrada en vigencia". 
jueces en un caso estimaron que la modificación era arbitraria, y en el otro, que no.

En Lobo, SERNAC con $V T R,{ }^{25}$ la Corte Suprema consideró que el arbitrio de la empresa fue manifiesto "... dado que el canal ha sido excluido del plan contratado sin rebajar el precio de éste, e incorporando luego a otra programación especial, a la que sólo puede accederse por un precio adicional" (considerando $3^{\circ}$ de la Corte Suprema y considerando $4^{\circ}$ de la Corte de Apelaciones de Santiago). Y tiene razón, puesto que consta en el proceso que se le ofreció al consumidor "mantener" el servicio, pero sin considerar una rebaja en el precio, ofreciéndole un valor extra por el canal extraído.

Así, es posible apreciar que la arbitrariedad consiste en las oscilaciones del proveedor respecto de la forma de cumplir con la obligación. La interdicción de la arbitrariedad está sancionada en materia de consumo, precisamente, por el grado de incerteza que producen casos como este, porque es arbitrario cambiar uno de los canales que tenía derecho a ver el consumidor haciéndolo pagar un precio extra si desea mantenerlo. Esto produce un menoscabo económico para el consumidor (considerando $3^{\circ}$ ).

La ratio decidendi del fallo es que no puede cobrarse un precio extra por algún elemento que forma parte integrante de la prestación (canal que estaba dentro de la grilla programática). Regla que, dicho sea de paso, cristaliza el reconocimiento del pacta sunt servanda del Código Civil, reconocido de manera especial en el artículo 12 de la LPDC.

Con anterioridad, en Bezanilla, SERNAC con $V T R,{ }^{26}$ por los mismos hechos descritos en la sentencia anterior, se llegó a la conclusión que se trataba de una cláusula y práctica lícita amparada por la LPDC. En este caso, las ponderaciones judiciales prefirieron los intereses del proveedor al validar sus justificaciones económicas.

Así, se consideró que no era arbitraria la extracción del canal, por criterios de razonabilidad. Es decir, que no resultaría razonable exigir a la compañía que mantenga inalterable en el tiempo su programación de canales. ${ }^{27}$ Para ello, se

${ }^{25}$ Corte Suprema, 18 de noviembre de 2008, Rol № 3528-08. En este caso, se ratificó la decisión del tribunal a quo y se rechazó la interposición del recurso de queja, porque la cláusula que facultaba a la empresa para realizar esta modificación unilateral no obedecía a "criterios racionales" o "decisiones de emisores de señales".

${ }^{26}$ Corte Suprema, 18 de mayo de 2009, Rol No 1672-09.

${ }^{27}$ Quizás este argumento merezca detención. En realidad, pienso que los empresarios deben asumir los mayores gastos en los contratos de larga duración, salvo que la prestación se vuelva excesivamente onerosa. 
esgrimió el estándar de "desarrollo del negocio" o crecimiento de la empresa, que a mi juicio puede tener relevancia en otro ámbito normativo, pero no para interpretar contra el consumidor las disposiciones especiales legales que lo tutelan; o al menos, no como se encontraba formulado en este caso, en que la cláusula manifestaba una imprecisión respecto del contenido de la prestación para el consumidor.

En suma, el primer criterio judicial que aparece es que no puede suprimirse parte de la prestación ofrecida al consumidor para exigir el pago de un precio adicional por ella.

ii. Alteraciones en los servicios educacionales. En el ámbito de la educación se da cuenta de cambios de prácticas laborales. En efecto, en sentencia de la Corte de Apelaciones de Antofagasta, ${ }^{28}$ se comprobó que no se realizaron las prácticas laborales declaradas en la malla curricular de la carrera de técnico en enfermería obstétrica. En su defecto, la entidad educacional ofreció la dictación de talleres de "práctica simulada" en el mismo instituto, como si fueran prácticas laborales. Por eso, la Corte de Apelaciones de Antofagasta consideró que esta modificación unilateral no fue abusiva, al sentenciar que: “... dicha malla es naturalmente flexible, hecho que fue aceptado por las querellantes al suscribir los contratos de prestación de servicios educacionales [...] Ellas sabían desde el inicio que la proposición de la malla tenida a la vista al contratar, podía sufrir modificaciones $y$, en conocimiento de lo anterior, aceptaron la oferta de enseñanza". ${ }^{29}$

Lamentablemente no aparece la descripción de la cláusula en entredicho, lo único que da cuenta el fallo es un folleto publicitario que detalla las características de la carrera ofrecida. En ese documento se apreciaba con letra chica que la malla estaba sujeta a modificaciones. Aun cuando no se conocen más antecedentes, se infiere que el criterio que permitió excluir las infracciones a la ley (no se discutió la abusividad) en este caso particular dice relación con aceptación de las nuevas condiciones contractuales o de una supuesta "flexibilidad" de ella. En efecto, la Corte sostuvo que "Esta circunstancia de flexibilidad en las mallas curriculares, es una práctica habitual en los programas de estudios, sea de institutos, universidades $u$ otros establecimientos educacionales y que responden

\footnotetext{
${ }^{28}$ Corte de Apelaciones de Antofagasta, 2 de noviembre de 2005, Rol No 122-2005.

${ }^{29}$ Así, el establecimiento educacional fue absuelto de la responsabilidad infraccional por la supuesta infracción a los artículos 12 y 23 de la ley, sin mencionar lo dispuesto en el artículo 16 letra a) LPDC. Junto con ello, se consideró que se trataba de una competencia excluida de la ley.
} 
a las diversas realidades a que se ven enfrentados" (considerando $4^{\circ}$, parte final).

No comparto la decisión de la Corte. Si en una cláusula aparece la expresión "sujeta a modificaciones" se trataría de un arbitrio puro prohibido en materia de consumo. Lo anterior no se relaciona con una supuesta flexibilidad respecto de la forma de cumplir la prestación. En realidad, con esta cláusula los consumidores no tienen cómo saber la forma en que se realizará la ejecución contractual. Por eso, respecto de este punto observo una de las consideraciones del tribunal, en orden a que la mera aceptación del consumidor no produce el efecto de validar la manera de ejecutar una cláusula predispuesta por el proveedor, menos si se tiñe de arbitrariedad, pues precisamente el control judicial represivo cuida de menguar el valor de esa aceptación. El juez de consumo debe asumir un rol tutelar.

Tampoco me parece que podría tener cabida para justificar la supuesta flexibilidad de la malla curricular el criterio de la ejecución práctica del contrato del artículo 1564 CC inciso 2do del Código Civil, que señala que las cláusulas de un contrato se interpretarán "por la aplicación práctica que hayan hecho de ellas ambas partes, o una de las partes con aprobación de la otra". Aunque esta regla de interpretación se ha calificado por Claro SolaR, ${ }^{30}$ como la "reina de todas las interpretaciones", estimo que no correspondería aplicarla en perjuicio del consumidor, por aplicación de la regla contra proferentem.

Sin embargo, como estas líneas tienen por objeto examinar los criterios judiciales habrá que señalar que la expresión "sujeta a modificaciones" ha sido considerada como una forma lícita de modificación unilateral de un contrato por adhesión en el ámbito educacional.

Dicho eso, a continuación corresponde revisar las sentencias que examinan los supuestos de modificaciones totales de la prestación.

b. Alteraciones totales de la prestación

En este grupo de casos la modificación unilateral se califica como absoluta, porque la cláusula se redactó de un sentido tal que permitía al proveedor realizar cualquier clase de alteración, en cualquier tiempo y momento. Por eso resulta, evidentemente, arbitraria:

i. Alteraciones en los servicios de espectáculos públicos. Es el caso SERNAC con Ticketmaster ${ }^{31}$ en que se discutió la legalidad de la cláusula

\footnotetext{
${ }^{30}$ Claro Solar, Luis, Explicaciones de Derecho Civil chileno y comparado. De las obligaciones III, Editorial Jurídica de Chile, Santiago, reimpr. 2013, T. XII, p. 28.

${ }^{31}$ Corte de Apelaciones de Santiago, 11 de noviembre de 2014, Rol № 4.835-2014.
} 
que establecía: "Ticketmaster, se reserva el derecho a cambiar estas Condiciones en cualquier momento, las cuales aplicarán inmediatamente después de que hayan sido publicadas en el Sitio".

Por la redacción de esta cláusula, y quizás por el argumento de la demandada en orden a que no se aplicaba la Ley del consumidor, ya que las condiciones de uso de la página web no eran contratos por adhesión, el tribunal de primera instancia sancionó esta cláusula.

Aquí, la arbitrariedad se verificó por la: "manifiesta falta de certeza y la situación de incertidumbre en la que se encuentran los consumidores [...] ya que de acuerdo a su redacción, éstas serían eminentemente transitorias y su contenido y vigencia dependería de la sola voluntad de la empresa demandada" (considerando $11^{\circ}$ ). Es decir, arbitrariedad pura. ${ }^{32} \mathrm{Y}$ lleva razón, puesto que una cláusula de este tipo debe ser mal calificada por las razones expuestas por el tribunal. La falta de determinación de la prestación provoca una falta certeza e incertidumbre.

La ratio decidendi del fallo es que la cláusula que autoriza a cambiar las condiciones en cualquier momento es ilícita en el ámbito de los servicios de espectáculos públicos, porque supedita el cumplimiento de la prestación al mero arbitrio del proveedor. Esta fórmula, a mi juicio, es similar a la cláusula que contiene la expresión "sujeta a modificaciones".

ii. Alteraciones en los servicios educacionales. Junto con ello, se han detectado dos fallos insertos en el ámbito educacional que modifican de forma absoluta la prestación, al incorporar condiciones especiales que niegan el ingreso al centro educacional.

Así, se ha calificado como abusiva una cláusula que deniega el ingreso a un curso de posgrado de la Universidad, si es que no cumple con un número mínimo de matriculados.

Se trata de Barrientos con Universidad de Arte y Ciencias Sociales ARCIS,,$^{33}$ que da cuenta que la denunciante fue aceptada en el curso de magíster, pero como en el contrato existía una cláusula que disponía: "se reserva a modificar unilateralmente el citado Plan de estudios, cuando existan razones académicas que así lo justifiquen", se dijo que no se había reunido el cupo mínimo necesario para impartir el curso. Por eso, la Universidad anuló la matrícula. ${ }^{34}$

\footnotetext{
${ }^{32}$ Así declaró la nulidad de las condiciones de uso del portal web y del ticket de entrada a los espectáculos públicos que repetía esa frase.

${ }^{33}$ Corte de Apelaciones de Santiago, 4 de noviembre de 2009, Rol No 10.892-2009.

${ }^{34} \mathrm{El}$ tribunal condenó la infracción al artículo 16 letra g) y b) de la ley, pero lo sancionó con una multa
} 
En este caso, la Corte de Apelaciones de Santiago consideró que los motivos invocados por el centro educacional no eran académicos sino económicos (considerando $10^{\circ}$ ). Por eso, incluso en carácter de obiter dictum, sentenció que si fueran razones académicas: “... la cláusula de reserva para modificar el programa docente contratado al emplear la expresión 'razones académicas', es de tal manera general y vaga, que prácticamente deja al arbitrio o razonamiento subjetivo de una persona al estimar que existen 'razones académicas"' (considerando 14 ${ }^{\circ}$ ).

Este fallo no se pronuncia sobre la arbitrariedad, que dicho sea paso es necesario probarla. ${ }^{35}$ Pero, de todas formas es posible inferir que ella se encuentra presente. Así, es posible comentar que aquí aparece la relación que tendría la arbitrariedad con la ausencia de motivos justificados, plausibles o razonables que deben describirse en el contrato por adhesión, tal como ocurrió en Ticketmaster (cambio de las condiciones en cualquier momento) o No se consigna (sujeta a modificaciones).

Así, la arbitrariedad se manifestaría en la carencia de razones. Y, en este sentido, es posible apreciar cómo esta forma de sanción se acerca a la noción constitucional que entiende que lo arbitrario sería, según Nogueira “... la falta de fundamento racional de un acto, cuando el acto se desarrolla por mero capricho, cuando hay falta de proporcionalidad entre el fin y los medios que se utilizan, cuando hay falta de hechos que justifiquen un proceder". ${ }^{36}$ Antes, Cea consideró que el término arbitrario "quiere decir contrario a la justicia, injusto, irracional, prejuiciado, desproporcionado para el fin querido, guiado o motivado por el capricho o la inquina...". ${ }^{37}$ Pinochet ${ }^{38}$ por su parte agrega la carencia de principios jurídicos. Sirvan, entonces, las directrices constitucionales para estimar cuándo surge la arbitrariedad en materia de consumo.

De este modo, la razón que decide el fallo es que la expresión "razones académicas" es arbitraria por ser general y vaga en el contexto educacional.

\footnotetext{
a beneficio fiscal de 30 UTM.

${ }^{35}$ Es necesario probar el aumento unilateral, pues de lo contrario el tribunal no estimará las pretensiones del actor, tal como ocurrió con Sánchez con Universidad del Mar, Segundo Juzgado de Policía Local de Copiapó, 27 de noviembre de 2007, Rol № 3296-2007, en que se invocaba una modificación unilateral y arbitraria de la carrera de ingeniería en prevención de riesgos de diurna a vespertina, pero sin acreditarlo de forma debida. En este caso, se acreditó más bien, que la reclamante había perdido su calidad de alumna regular por encontrarse morosa en el pago de la matrícula del año anterior.

${ }^{36}$ Nogueira Alcalá, Humberto, Derechos fundamentales y garantías constitucionales, Editorial Librotecnia, Santiago, 2013, 4ta edic. actualizada, T. I., p. 352.

${ }^{37}$ Cea Egaña, José Luis, Derecho Constitucional chileno, Ediciones UC, Santiago, 2012, T. II., p. 669.

${ }^{38}$ Pinochet Cantwell, Francisco José, El recurso de protección, Editorial El Jurista, Santiago, 2016, p. 128.
} 
A contrario sensu, una cláusula que permita la adaptación unilateral de la prestación no debe ser general, ni vaga.

El segundo caso detectado en Salas con Universidad Pedro de Valdivia, ${ }^{39}$ en que se consideraron lícitas ciertas condiciones predispuestas por el establecimiento educacional. En los hechos, la alumna se matriculó en Diseño gráfico, carrera que no se impartió por no alcanzar el número de matriculados. La Corte desestimó la denuncia y demanda civil, por las gestiones que hizo la Universidad para reubicar a la alumna en otro centro educacional. ${ }^{40}$

El fallo describe el Reglamento de Prestación de servicios. Este documento establecía en la cláusula tercera que la universidad se reservaba el derecho a no impartir asignaturas correspondientes al primer año, si no se reunían el número mínimo de alumnos matriculados para tal efecto (considerando 5to). Aquí no aparece mención alguna a razones académicas o económicas.

La Corte de Santiago consideró que dicha situación no generaba ninguna infracción a la LPDC, porque calificó la cláusula como una condición resolutoria ordinaria lícita, mixta, posible (considerando $7^{\circ}$ sentencia primera instancia). Debo observar la calificación de la condición como mixta, por el supuesto el acaso que exige su configuración (artículo 1477).

En este caso, también observo el criterio judicial, pues la cláusula no pende de un acaso, ni tampoco es lícita. Con ella se deja al mero arbitrio de la Universidad la forma de cumplir con la prestación, igual como ocurre en el caso anterior, en que además se describe que no basta señalar fórmulas vagas o generales. Destaca la actitud de la proveedora de celebrar una clase de "operación de reemplazo" en aras de reubicar a la alumna. Quizás por esta razón se desestimaron las pretensiones demandadas.

Entonces, para concluir el análisis de las interpretaciones judiciales que controlan las cláusulas de modificación unilateral relacionada con la prestación, hay que señalar que la arbitrariedad se construye en la praxis judicial mediante la inserción de cláusulas ambiguas o generales, que intentan dejar en la incertidumbre al consumidor provocándole un perjuicio. Dicho eso ahora corresponde examinar la forma de la modificación unilateral relacionada con el pago del precio del consumidor.

\footnotetext{
${ }^{39}$ Corte de Apelaciones de Santiago, 13 de agosto de 2008, Rol No 4192-2008.

${ }^{40}$ Como por vía de absolución de posiciones se demostró que los dependientes del proveedor habían realizado gestiones para incorporar a la alumna en otra casa de estudios, y ella que reconoció que no había pagado ninguna suma de dinero a la Universidad querellada y demandada, se absolvió de responsabilidad infraccional y civil al centro educacional.
} 


\section{Modificación unilateral relacionada con el precio}

Para avanzar, corresponde decir que en estos casos una cláusula predispuesta por el proveedor provoca una alteración en el pago de los servicios, siempre al alza. Se trata de un intento de (a) cobrar más por el mismo servicio, (b) cobrar aunque no se preste el servicio, o (c) aumentar el cobro de la comisión por los servicios prestados.

\section{a. Aumento del precio por el mismo servicio}

De este grupo de casos es posible observar que el razonamiento judicial identifica la siguiente regla: "si el servicio prestado conserva las mismas características, no puede aumentarse el precio". Lo que precisado, aún más, implica que: "sólo puede aumentarse el precio cuando se acepta una prestación diversa y adicional a la contratada".

Con ello, se produce, en la judicatura, una unión del criterio de la arbitrariedad del artículo 16 a), objeto de este estudio, con lo dispuesto en el literal b) que proscribe las cláusulas que: "establezcan incrementos de precio por servicios, accesorios, financiamiento o recargos, salvo que dichos incrementos correspondan a prestaciones adicionales que sean susceptibles de ser aceptadas o rechazadas en cada caso y estén consignadas por separado en forma específica".

Bajo este apartado se han sistematizado sentencias que examina el ámbito de los servicios de internet, telefonía, prestaciones relacionadas con la salud y tiempos compartidos:

i. Servicios de internet. En Álvarez, Sernac con Terra Networks, ${ }^{41}$ el SERNAC denunció y el usuario demandó a la empresa la modificación unilateral del precio que sufrió el uso de los servicios de internet contratados. Por su parte, la defensa del denunciado-demandado se basó en que se trataba de un aumento por concepto de "reajustes". ${ }^{42}$

La Corte de Apelaciones de Santiago, con buen juicio, desestimó esta

${ }^{41}$ Corte de Apelaciones de Santiago, 12 de enero de 2005, Rol No 3759-2003.

${ }^{42}$ Lo curioso de este caso fue que la defensa del denunciado aceptó el aumento de precio, pero argumentó que entre las partes no había un contrato que los uniera, sino que sólo un acto unilateral del usuario que accedía a: "un portal de libre acceso"; y que, por eso, no podían identificar al usuario. Pero que, de todas formas, se avisó del cambio de tarifas en los términos y condiciones de la página web. La Corte de Santiago condenó a la empresa denunciada a pagar una multa infraccional de 30 UTM. Y en la parte civil desestimó la indemnización de perjuicios por falta de prueba. No se solicitó la nulidad del acto. 
alegación al constatar que no fue aceptada por el usuario; y que, además, tal modificación no estaba predispuesta en el contrato por adhesión. Incluso, en carácter de obiter dictum sentenció: "que evidentemente no se está sosteniendo que al proveedor le está prohibido por siempre reajustar las tarifas, sino solamente que tal incremento debe hacerse en la oportunidad, con la periocidad y en la forma y monto indicados en el contrato de adhesión original. Lo que no es aceptable, como por lo demás lo prohíbe expresa y perentoriamente la ley, es que ello quede entregado al arbitrio del proveedor" (considerando $10^{\circ}$ sentencia primera instancia).

Y si bien la Corte lleva razón en la parte que señala las características de la modificación lícita del contrato siempre y cuando sean definidas y razonadas (no sólo como lo señala el contrato), observo que el alza de precio no constituye un reajuste.

Así, este fallo mostraría que es arbitrario cobrar más por el mismo servicio. Junto con ello, el alza de precio no es un reajuste. ${ }^{43}$

ii. Servicios telefónicos. En el ámbito telefónico existen una serie de denuncias interpuestas por el SERNAC basadas en los mismos hechos: la empresa Telefónica Móvil intentó subir el precio de los planes. Y al igual que en el caso anterior, se intentó disfrazar el aumento de precios mediante un supuesto reajuste.

El año 1998, los demandantes celebraron un contrato de prestación de servicios telefónicos móvil de 90 minutos por la suma de \$8.500. Luego, el año 2001 recibieron una carta de la empresa que informaba el alza del plan a $\$ 12.200$. La empresa ofrecía, además, una alternativa para mantener el valor pagado, a través de otro plan pero con menos prestaciones. Esta modificación unilateral implicaba un aumento del $44 \%$ del valor del precio del plan contratado. En estos casos, se denunciaron las infracciones a los artículos 16 letras b) y g), 12 y 23 de la LPDC.

La cláusula 4ta del contrato en entredicho establecía que las tarifas y precios podían ser modificados por la empresa. Esta circunstancia debía ser informada al cliente mediante el documento de pago inmediatamente anterior a la entregada en vigencia de las nuevas tarifas.

Así, en Aravena, SERNAC con Telefónica Móvil, ${ }^{44}$ se sancionó con

\footnotetext{
${ }^{43}$ Existe un caso reciente del ámbito financiero que trata la misma cuestión: Servicio Nacional del Consumidor con Créditos Organización y Finanzas S.A., Corte Suprema Primera Sala, 8 de octubre de 2015, Rol N² 27802-2014.

${ }^{44}$ 1er Juzgado de Policía Local de Santiago, 17 de octubre de 2005, Rol No 14.323-2002.
} 
una multa de 10 UTM porque se estimó que se trataba de un alza de precio y no de un reajuste que actualizara el plan (considerando décimo); 5 UTM en Bustamante, SERNAC con Telefónica Móvil ${ }^{45}$ y en Cuevas, SERNAC con Telefónica Móvil, ${ }^{46}$ en que se cambió unilateralmente el monto del plan de $\$ 7.000$ a \$9.000; 15 UTM en Finch, SERNAC con Telefónica Móvil; ${ }^{47}$ Herrera, SERNAC con Telefónica Móvil; ${ }^{48}$ Canales, SERNAC con Telefónica Móvil; $;{ }^{49}$ Fernández, SERNAC con Telefónica Móvil ; ${ }^{50}$ Leñero, SERNAC con Telefónica Móvil; ${ }^{51}$ Manríquez, SERNAC con Telefónica Móvil; ${ }^{52}$ Molina, SERNAC con Telefónica Móvil ${ }^{53}$ Repol, SERNAC con Telefónica Móvil ${ }^{54}$ y Rivera, SERNAC con Telefónica Móvil. ${ }^{55}$

La ratio decidendi de los fallos es que es arbitrario cobrar más por el mismo servicio.

$\mathrm{Y}$ al igual que el caso anterior sorprende que se haya intentado disfrazar un alza de precio mediante un reajuste ficticio. CASTELBLANCO,${ }^{56}$ tiempo atrás, planteaba que de aceptar la reajustabilidad de una obligación restitutoria de una suma de dinero habría que hacerse cargo del período del reajuste y forma de cálculo. Al parecer, ninguna de estas consideraciones realizaron las empresas analizadas, sólo se alzó el precio.

iii. Servicios de salud. En el ámbito de salud también se ha encontrado una cláusula abusiva por aumento unilateral del precio. Y, al igual que en el ámbito de los servicios de internet y los servicios telefónicos se intentaba simular un alza de precio mediante el establecimiento de un supuesto reajuste.

\footnotetext{
${ }^{45}$ 1er Juzgado de Policía Local de Santiago, 20 de octubre de 2005, Rol No 12.004-2002.

${ }^{46}$ 1er Juzgado de Policía Local de Santiago, 17 de octubre de 2005, Rol No 12.001-2002.

47 1er Juzgado de Policía Local de Santiago, 27 de diciembre de 2005, Rol No 12.712-2002.

48 Ídem.

49 1er Juzgado de Policía Local de Santiago, 30 de enero de 2006, Rol No 19.583-2003.

${ }^{50}$ 1er Juzgado de Policía Local de Santiago, 30 de enero de 2006, Rol No 12.712-2002.

${ }^{51}$ 1er Juzgado de Policía Local de Santiago, 10 de mayo de 2006, Rol No 10.909-2002.

52 1er Juzgado de Policía Local de Santiago, 20 de febrero de 2006, Rol No 183-2004.

53 1er Juzgado de Policía Local de Santiago, 20 de enero de 2006, Rol № 9970-2002.

${ }^{54}$ 1er Juzgado de Policía Local de Santiago, 27 de diciembre de 2005, Rol No 10.580-2002.

55 1er Juzgado de Policía Local de Santiago, 27 de diciembre de 2005, Rol № 5.890-2003.

${ }^{56}$ Castelblanco Koch, Mauricio, Las obligaciones restitutorias del Código Civil y la inflación, Editorial Jurídica de Chile, Santiago, 1979, p. 79.
} 
Se trata de Fernández con Banmédica $S . A .^{57}$ en que la Isapre pretendía un aumento del valor del plan bajo la fórmula del "reajuste de la salud" ${ }^{58}$ Aquí, se consideró que se trataba de una clase de modificación arbitraria, porque aumentaba en un $46 \%$ el plan de salud (el valor base del plan más el factor etáreo), disminuyendo los beneficios contratados a través de menores prestaciones, sólo por razones de edad (al cumplir 61 años). Así se sentenció que no habían “... justificaciones reales, en el sentido que el aumento signifique para él una mejora en su plan expresado en mejores o mayores beneficios que aquellos de los cuales ya gozaba, no pudiendo sostenerse que por el simple hecho de cumplir una determinada edad cause a aquella [Isapre] mayores desembolsos los que, a juicio de este Tribunal, la denunciada debió señalar con absoluta precisión, cosa que no ha hecho durante el juicio; o al menos, presentar al afiliado las condiciones que hacían plausible la adecuación de su plan de salud para que éste, voluntariamente, lo aceptara o rechazara..." (considerando $6^{\circ}$ ).

Con ello, el criterio de la arbitrariedad se muestra de forma clara: no hay justificaciones reales, en palabras del tribunal, que toleren el alza de precio. Asimismo, destaco que el tribunal haya señalado que para que proceda un aumento de este tipo deben demostrarse las condiciones precisas que lo hacen plausible. Así, el consumidor -manifestando su voluntad- las aceptará o rechazará.

No puedo dejar de mencionar que sorprende la forma coincidente de intentar hacerlo a través de un mal llamado reajuste. En efecto, si el incremento del precio resulta algo difícil de justificar en el ámbito del consumo, incluso en contratos de larga duración o de duración indefinida, no puede tolerarse que el proveedor intente disfrazar modificaciones arbitrarias de este elemento en una cláusula predispuesta de un contrato por adhesión como si fueran una forma de indexación o adaptación de la moneda, porque no lo son. ${ }^{59}$

\footnotetext{
${ }^{57}$ Corte Suprema, 14 de enero de 2010, Rol No 9.029-09.

${ }^{58}$ Por este motivo, la Corte Suprema dejó sin efecto la cláusula e indemnizó al afiliado consumidor con $\$ 5.000 .000$, condenando a la empresa con una multa de 30 UTM.

${ }^{59}$ En realidad, si un proveedor intenta modificar el precio al alza se produciría una forma de indeterminación del precio, que pugnaría con la regla establecida en el artículo 1809 parte final del Código Civil en términos que "No podrá dejarse el precio al arbitrio de uno de los contratantes" y con las reglas que disciplinan la forma de determinación del objeto de la prestación ex artículo 1461 del Código Civil. Junto con ello, existirían posibles infracciones a otras reglas propias de la ley, relacionadas con el cumplimiento de deberes de información. La primera sería el derecho que le asiste al consumidor de tener una información veraz y oportuna sobre el precio (artículo 3 letra b). También se configuraría una sanción infraccional especial cuando se produce un "cobro de un precio superior al exhibido, informado o publicitado" (artículo 18). Y el artículo 30 inciso $2^{\circ}$ señala que el precio "deberá indicarse de un modo claramente visible que permita al consumidor, de manera efectiva, el ejercicio
} 
Por otra parte, se conoce un caso que considera una serie de factores objetivos que permitirían validar el aumento del precio originalmente ofrecido. Se trata de Contreras con Hospital Clínico de la Universidad de Chile ${ }^{60}$ en que la denunciante y demandante solicitó un presupuesto para realizarse una operación médica (by-pass gástrico). Con dicha cotización, se realizó la operación y luego invocó el cobro de un precio mayor al informado y publicitado. La diferencia era de $\$ 1.154 .975$.

La defensa que interesa examinar en estos momentos dice relación con lo señalado en la cotización. Ese instrumento, que le fue entregado antes de la operación, establecía que: "los valores indicados en este presupuesto corresponden a una estimación del gasto de hospitalización, sin embargo la cuenta definitiva puede variar de acuerdo a la evolución del estado de salud del paciente, la complejidad de la intervención quirúrgica si la hubiere y los insumos especiales utilizados en esta última". Así, la Corte Suprema acogió el recurso de queja interpuesto por el querellado y desestimó la condena infraccional. En las instancias anteriores se había desestimado la indemnización de perjuicios.

Como se ha expuesto, ${ }^{61}$ esta categoría contractual se enmarca dentro del ámbito de los servicios de consumo masivo, pero no hay que desatender que se cuida la salud, seguridad y la persona misma del paciente-consumidor. Así, parecen atendibles los descargos de la demandada en orden a que el médico tratante dispuso de insumos especiales considerando el estado de la paciente, las instrucciones preoperatorias y los hábitos alimenticios de la consumidora.

Entonces, el empleo de prestaciones adicionales no contempladas en el contrato (presupuesto en realidad) justificaría la necesidad de revisar el precio cobrado a la paciente, puesto que en este caso, la modificación se debió a los mayores insumos que determinó el facultativo responsable de la operación. Por eso, aquí se observa una hipótesis de modificación unilateral lícita del precio inicialmente ofrecido en un presupuesto del proveedor.

iv. Servicios de tiempos compartidos. Ya situados en el mercado de los tiempos compartidos se encuentra Camus con Comercializadora con Aldo Manatagua S.A. ${ }^{62}$ En los hechos, se discutió una cláusula que autorizaba el incremento de precio por servicios y otra que facultaba a la empresa a modificar el monto de las cuotas a pagar. Así, la Corte de

de su derecho a elección, antes de formalizar o perfeccionar el acto de consumo".

${ }^{60}$ Corte Suprema, 6 de enero de 2012, Rol No 8.905-2011.

${ }^{61}$ Barrientos, cit. (n. 16), pp. 459-461.

${ }^{62}$ Corte de Apelaciones de Santiago, 21 de septiembre de 2007, Rol № 3.746-2007. 
Apelaciones de Santiago sentenció que todas las cláusulas del contrato debían analizarse según el criterio general de la buena fe consagrado en el artículo 16 letra g) LPDC, lo que comparto.

De este modo, dictaminó que el criterio integrador de la abusividad eran las "expectativas razonables", lo que en sus palabras era lo que "razonablemente podría haberse hecho respecto del contrato" (considerando $1^{\circ}$ y $14^{\circ}$ ). Y por ese motivo rechazó el aumento de precio predispuesto en la cláusula por la empresa de tiempos compartidos. A propósito de esto, De la Maza ${ }^{63}$ considera que dichas expectativas razonables se encuentran presentes en el artículo 16 letra g) LPDC, que opera como un criterio orientador para calificar la abusividad de las cláusulas. Entonces, a fortiori, dichas expectativas razonables pueden incardinarse también en la letra a) del artículo 16 de la ley para calificar la arbitrariedad.

Para finalizar el examen del aumento del precio por el mismo servicio hay que decir que las modificaciones que tienden al alza del precio haciéndolos pasar por reajustes deben calificarse de abusivas por arbitrarias. Según las Cortes no hay razones reales para sustentar la validez de esta estipulación contractual. También se fundamentan las alzas de precios en la frustración de las expectativas razonables del consumidor.

Dicho esto, ahora corresponde estudiar la segunda categoría de sentencias relacionada con el precio: el cobro aunque no se preste el servicio.

\section{b. Cobro del precio aunque no se preste el servicio}

Y, aunque parece curioso, suele suceder que algunas empresas proveedoras intentan seguir cobrando, aun cuando no prestan el servicio. No me refiero a una hipótesis de suspensión de la prestación por mora o incumplimiento del consumidor, ${ }^{64}$ sino a supresiones de la prestación que nacen por cláusulas ubicadas en el ámbito de la educación, servicios de espectáculos públicos, aerolíneas y deportivos:

i. Servicios de educación. En el ámbito de la educación se ha intentado cobrar la prestación, aun cuando no se preste el servicio e incluso

\footnotetext{
${ }^{63}$ DE LA MAZA, Iñigo, “¿Pero qué es lo que esperabas? Contratos por adhesión y expectativas razonables”, en: Turner, S.; Varas, J.A. (coords.), Estudios de Derecho Civil IX, Legal Publishing- Thomson Reuters, Santiago, 2014, p. 342.

${ }^{64}$ Que se encuentra regulada en el artículo 25 inciso final de la ley, que establece: "El proveedor no podrá efectuar cobro alguno por el servicio durante el tiempo en que se encuentre interrumpido y, en todo caso, estará obligado a descontar o reembolsar al consumidor el precio del servicio en la proporción que corresponda".
} 
una alumna invocó circunstancias especiales para no seguir pagando la matrícula.

Así, se ha intentado cobrar a todo evento, en Parra con Universidad Andrés Bello. ${ }^{65}$ De los hechos se da cuenta que la Universidad no realizó el servicio, pero pretendió el pago.

Lamentablemente, la sentencia no transcribe la cláusula, ni señala por qué no se prestó el servicio, pero al menos deja claro: "Que el pago de la matrícula y la colegiatura anual constituyen la contraprestación en dinero de ese servicio, pero no aparece del contrato, ni se ha sostenido como argumento por la demandada, que éste constituya la finalidad del contrato" (considerando $\left.8^{\circ}\right)$. Por esta razón, el sentenciador declaró la nulidad de la cláusula que exigía el pago a todo evento.

Con este nuevo criterio se apreciaría cómo la arbitrariedad se relacionaría con la ausencia de criterios que atiendan a la finalidad del contrato; parámetro que coincide con lo establecido en el artículo 16 letra g) de la ley. De este modo, se considera arbitrario pagar si no se prestan los servicios. Esto es una manifestación propia del sinalagma contractual reconocida en el artículo 1552 del Código Civil.

Para avanzar, conviene mencionar que una enfermedad que padece un alumno, que le impide asistir a clases, puede operar como una causal que exime la obligación de pago. Es cierto que este tema no dice relación con la modificación unilateral de parte del proveedor, pero merece la pena examinar, a efectos de delinear algunos límites de la abusividad.

En Hubner y otro con Universidad Mayor ${ }^{66}$ se pretendió el cobro de precio aun cuando se certificó que la enfermedad de la alumna le impedía asistir a clases. En los hechos, se acreditó la condición psiquiátrica que le afectaba. Por esa razón, la Corte de Santiago acogió la demanda e hizo cesar la obligación de pago de las mensualidades, a contar del mes de mayo de $2003 .{ }^{67}$ Por su parte, en Álvarez con Universidad Finis Terrae ${ }^{68}$ se obligó al

\footnotetext{
${ }^{65}$ Corte de Apelaciones de Santiago, 5 de julio de 2008, Rol No 2335-2008.

${ }^{66}$ Corte de Apelaciones de Santiago, 1 de julio de 2008, Rol No 8775-2004.

${ }^{67}$ Aunque hay que señalar que la fundamentación del fallo se encuentra alejada de las facultades unilaterales y la arbitrariedad. En efecto, uno de los dictum de este fallo se basa en la falta de veracidad del acuerdo celebrado y la infracción pacta sunt servanda ex artículo 1437 del Código Civil. A mi juicio, no se trata de un problema de veracidad de la voluntad (considerando $3^{\circ} \mathrm{N}^{\mathrm{o}} 1$ ), aplicación del derecho de retracto (considerando $3^{\circ} \mathrm{N}^{\mathrm{o}} 3$ ) o cobros extrajudiciales. En realidad, todo indica que en este fallo primaron los argumentos de equidad (considerando $6^{\circ}$ ).

${ }^{68}$ 3er Juzgado de Policía Local de Providencia, 15 de diciembre de 2006, Rol № 7997-4-2006.
} 
apoderado seguir pagando, sin sopesar que había perdido su trabajo. La cláusula en entredicho establecía: "El contratante estará obligado a pagar oportunamente el total de la suma acordada por el período completo convenido, aun cuando el alumno no hiciere uso del servicio educacional contratado, por cualquier causa, tales como retiro, suspensión o anulación de períodos académicos no precediendo devolución, imputación ni compensación alguna, toda vez que la Universidad ha adquirido compromisos académicos y económicos para la prestación de los servicios contratados...".

Y aunque la discusión se centró en el análisis del artículo 16 letra g), en concreto sobre el desequilibrio y la naturaleza contractual, en realidad se trata de un problema de modificación unilateral propuesta por el consumidor jurídico que invocaba necesidades especiales para eximir el pago. En rigor, la ausencia de trabajo o de recursos económicos no exime el pago. Si el deudor cae en insolvencia se activan una serie de medidas en el Código Civil,${ }^{69}$ que procuran resguardar los bienes del deudor frente a eventuales procesos concursales. ${ }^{70}$

Quizás por razones pragmáticas más que otros pareceres, el tribunal sostuvo que: “... parece necesario convenir que no se puede aceptar el retiro de los alumnos a medio año -por alguna circunstancia- como causal de exención de pago ya que ello traería pronto, como consecuencia, el término del establecimiento educacional por falta de financiamiento" (considerando $9^{\circ}$ ). De todas formas, observo la amplitud y vaguedad de la cláusula examinada, pues permite el cobro "por cualquier causa", sin que proceda devolución alguna, lo que podría generar una clase de arbitrariedad.

ii. Servicios de espectáculos públicos. Ahora bien, en materia de espectáculos públicos se ha pretendido mantener el cargo por servicio, aun cuando no se realice el evento contratado.

Se trata de Villar con Ticketmaster, ${ }^{71}$ en que se declaró abusiva una cláusula que negaba la restitución del cargo por servicio, pese a la anulación del espectáculo público. ${ }^{72}$

\footnotetext{
${ }^{69}$ ABELIUK señala que se producen las caducidades de los plazos; la separación judicial de bienes; la disolución de la sociedad; expiración del mandato; surge un supuesto de incumplimiento preventivo; nace la acción pauliana, en Abeliuk MANASEvich, René, Las obligaciones, Thomson Reuters, Santiago, 2014, 6ta edic. actualizada, T. II., pp. 1134-1135.

${ }^{70}$ Ruz LÁrtiga, Gonzalo, Nuevo Derecho Concursal chileno. Procedimientos concursales de empresas y personas deudoras, Thomson Reuters, Santiago, 2017, p. 479 y ss.

${ }^{71}$ Corte de Apelaciones de Santiago, 30 de septiembre de 2009, Rol No 10126-2009.

${ }^{72}$ Se declaró la nulidad de la cláusula que facultaba a la empresa a retener el cargo por servicio cuando se anulaba una función. Por eso, condenó a la empresa con una multa de 2 UTM y ordenó la restitución
} 
No se señala la cláusula en la sentencia comentada, pero sí las alegaciones de la empresa en orden a que reconoció la negativa a restituir los dineros solicitados porque se trataba de un servicio prestado "directamente" por Ticketmaster.

Entonces, se vuelve a reafirmar que la arbitrariedad se manifiesta en un desequilibrio de las prestaciones, al intentar cobrar el precio sin prestar el servicio.

iii. Servicios de transporte aéreo. Por otra parte, en materia aeronáutica no se ha permitido tomar el tramo de vuelta cuando no se ha volado en el tramo de ida.

En efecto, en Jarpa con Lan, ${ }^{73}$ se denunció la negativa de la empresa de permitir que una pasajera (la hija del querellante y demandante civil) arribe al tramo de regreso, porque no había utilizado el tramo de ida entre la ciudad de Santiago a Concepción. ${ }^{74}$

La defensa de la empresa invocó la existencia de la siguiente cláusula: "Uso del pasaje: Los vuelos que componen el itinerario deberán volarse en el orden correlativo indicado. Se negará el embarque a un pasajero que no cumpla con el orden antes referido o si el pasajero no ha volado alguno de los tramos indicados en su pasaje. Si no vuela alguno de los tramos indicados en el itinerario, el itinerario se cancelará en su totalidad, no procediendo ningún tipo de reembolso, salvo que las condiciones de la tarifa de su pasaje lo permitan. A modo de ejemplo, si Ud. no vuela el primer tramo que se especifica en el itinerario (entendiéndose como ida), no podrá volar ningún otro (entendiéndose como vuelo de escala o de vuelta). El ticket que Ud. ha comprado es intransferible".

Si bien esta sentencia en ningún momento refiere a la modificación unilateral y arbitraria, pienso que avanza en las consideraciones que deben tenerse a la mano para calificarlo, porque lo relaciona con el enriquecimiento injustificado y la renuncia de los derechos del consumidor.

Así, la ratio decidendi de esta sentencia es que el empresario no puede limitar los derechos adquiridos por el consumidor que compra pasajes de ida

de lo cobrado (\$76.000) más reajustes.

${ }^{73} 2$ do Juzgado de Policía Local de Las Condes, 18 de enero de 2010, Rol No 73.645-5-2009.

${ }^{74}$ De este modo, ni la excepción de incompetencia, ni la declaración estándar que entiende que el cliente acepta los términos, o que éstos estaban a disposición de cualquiera en la página web sirvieron para desestimar esta modificación ilícita. Por eso el tribunal multó a la empresa con 15 UTM y condenó civilmente, pero en los registros no aparecen los montos indemnizados. 
y de vuelta. En efecto, el tribunal entendió que el dinero pagado por los dos tramos aéreos habían ingresado al patrimonio de la empresa, por lo que no puede negarse el cumplimiento de la prestación. Junto con ello, reconoce que los derechos de los consumidores pueden ejercerse de la manera que ellos estimen conveniente, por eso pueden renunciar de forma parcial. Pero dicha abdicación no implica una renuncia total, como pretende acusar en este caso la empresa proveedora.

De esta forma, la modificación arbitraria se manifiesta en la forma del perjuicio al consumidor, el enriquecimiento sin causa y la imposibilidad de disponer de forma libre de sus derechos.

iv. Servicios deportivos. Por otra parte, en el fallo colectivo SERNAC con Gimnasios Pacific Fitness Chile Ltda. ${ }^{75}$ se declararon una serie de cláusulas abusivas por contener estipulaciones que favorecían la modificación unilateral y arbitraria. ${ }^{76}$

En los hechos, el SERNAC recibió múltiples reclamos a causa del cierre no informado de tres sedes del gimnasio, en circunstancias que siguieron cobrando por el servicio que no prestaban.

La cláusula segunda del contrato estipulaba que: "Las únicas causales que dan derecho a un socio a reembolsar cantidades que hubiera pagado por planes Trimestrales, Semestrales o Anuales, excluyendo de todo reembolso la matrícula, son: 2.1 Muerte del socio, debidamente acreditada a través del certificado de defunción del mismo. 2.2. Incapacidad física de por vida del socio".

En este caso, la Corte de Apelaciones revocó la decisión del a quo, al considerar que, de emplearse el criterio restrictivo de primera instancia que interpretó en sentido literal y exegético la cláusula, se trataría de una renuncia anticipada de sus derechos, generando un desequilibrio entre las partes, causándole un perjuicio al consumidor (considerando $4^{\circ}$ ).

De este modo, la cláusula de modificación unilateral será arbitraria

\footnotetext{
${ }^{75}$ Corte de Apelaciones de Santiago, 11 de mayo de 2015, Rol No 1693-2015.

${ }^{76} \mathrm{Sin}$ argumentos que permitan identificar el examen de la ilicitud de las cláusulas, el tribunal de primera instancia consideró "que en caso alguno producen el equilibrio de derechos entre los contratantes" las cláusulas que permiten exonerarse de aclarar el pago o informar morosidades ajenas a la finalidad del contrato. Asimismo, se calificó como abusiva la disposición que permitía establecer unilateralmente las clases de spinning que diariamente ofrecerá al público y su disponibilidad. Por estas y otras razones, se condenó la nulidad de ciertas cláusulas del contrato, las restituciones procedentes, una multa genérica de 50 UTM por la infracción cometida y no por cada afectado, sin indemnización de perjuicios por falta de prueba.
} 
cuando suponga una renuncia de sus derechos.

Para terminar, hay que estudiar la modificación relacionada con el aumento del precio de la comisión por servicios.

c. Aumento de la comisión por mantención de los servicios

En este grupo de casos resulta interesante mostrar cómo ha operado el aumento de la comisión por mantención de los servicios en sectores ajenos al financiero:

i. Servicios funerarios. En Ureta, SERNAC y La Administradora del Prado y La Foresta S.A., ${ }^{77}$ se denunció a la empresa el aumento de la comisión por mantención de servicios del contrato de compraventa de derechos de sepultación. En el contrato y los reglamentos se incorporó una cláusula que fijaba el precio de la comisión por mantención en 1 UF. Por su parte, la defensa alegó que el valor de la comisión se había "reajustado" progresivamente hasta llegar a 1,18 UF. Y, una vez más, salta a la vista esta práctica de confundir los reajustes con el aumento del precio.

Como en el contrato y los reglamentos se establecía un monto determinado, fue fácil para los tribunales constatar el aumento unilateral. Así, la Corte de San Miguel sentenció que la cláusula que toleraba tal aumento constituía una infracción al artículo 16 letra b), que proscribe el aumento de precio al consumidor sin obtener mejoras de los servicios. Por eso, revocó la sentencia de primera instancia y condenó con una multa de 25 UTM.

Resulta interesante mencionar que el juez de primera instancia consideró, en carácter de obiter dictum, que debía aplicarse el artículo 1564 del Código Civil, que autoriza a modificar el contrato por la "aplicación práctica" que las partes hayan dado, toda vez que el consumidor pagó desde 1993 hasta la época del juicio (2007) ese valor aumentado. Y sobre el particular, se puede mencionar que las reglas civiles deberían aplicarse en beneficio del consumidor, pero no en su perjuicio por la regla contra proferentem. De manera que sólo podría tolerarse la aplicación práctica de la ejecución contractual cuando el consumidor quiera y conozca, de manera inequívoca, la modificación pretendida.

Ese mismo año, en Peña y otros, SERNAC con Cementerio Parque Santiago (El retiro inmobiliaria e inversiones S.A.), ${ }^{78}$ se denunció y algunos demandaron la responsabilidad civil de la empresa por el aumento unilateral en

\footnotetext{
${ }^{77}$ Corte de Apelaciones de San Miguel, 13 de agosto de 2007, Rol No 484-2007.

${ }^{78}$ Corte de Apelaciones de Santiago, 18 de julio de 2007, Rol No 3040-2007.
} 
la comisión de servicios. Así, al igual que en Ureta, se sentenció que el contrato no podía ser modificado de forma unilateral mediante el establecimiento de cláusulas no especificadas en el formulario (considerando $9^{\circ} \mathrm{d}$ ). Con ello, se multó a la empresa con 50 UTM y se rechazaron las demandas indemnizatorias que solicitaban daño moral por falta de prueba. Del mismo modo, años más tarde, en Llefi Llefi y otros con Administradora de Parques Dobro Ltda. ${ }^{79}$ con similares argumentos, la Corte de Apelaciones de Valdivia confirmó la condena por 30 UTM y sentenció al pago de $\$ 250.000$ para algunos demandantes y con $\$ 100.000$ para otros.

Y, una vez más, en todas estas sentencias aparece la noción del perjuicio económico como el criterio que determina la arbitrariedad. Aquí también se pretende aumentar el cobro por la comisión por el mismo servicio prestado.

Por otra parte, resulta necesario destacar la existencia de un fallo que muestra la relevancia de la finalidad de la contratación. Se trata de Livacic con Cementerio Parque de Rengo ${ }^{80}$ en que los consumidores no sólo pretendían mantener inalterable el valor de la comisión por servicio, como en los casos anteriores, sino que querían dejar sin efecto el cobro de la comisión. ${ }^{81}$

En este caso, interesa destacar que el tribunal realizó un análisis de la finalidad de la comisión y del contrato celebrado. Así, explicó que los cementerios parque suponen la creación de un parque que tiene sepulturas. Por ello, era de la esencia la mantención de áreas verdes que cubren las sepulturas de esos parques. Y con ello, marca una diferencia con los cementerios públicos, en los cuales no existe esta obligación de pago, pues no rige el principio de igualdad de las personas muertas. En los cementerios públicos cada deudo

\footnotetext{
${ }^{79}$ Corte de Apelaciones de Valdivia, 1 de marzo de 2012, Rol № 237-2011. En este caso, el Servicio Nacional del Consumidor denunció 3 infracciones. Primero, la modificación del contrato relacionada con el servicio de sepultación y mantención producida antes de la entrada en vigencia del reglamento de cementerios aprobado por el Ministerio de Salud; segundo, la aplicación de IVA al servicio de mantención; y, tercero, el aumento del cobro de la comisión equivalente al 30\% más IVA.

${ }^{80}$ Juzgado de Policía Local de Rengo, 14 de marzo de 2007, Rol No 173.969.

${ }^{81}$ Incluso, se ventiló otra cuestión más difícil de examinar, que dice relación con una especie de resolución por incumplimiento del pago pero con efectos sui generis. En efecto, en el contrato se establecía que en caso de no pago de prácticamente cualquier prestación del cliente, la empresa estaba facultaba para exhumar los restos y trasladarlos a fosas comunes, sin consentimiento o notificación de ninguna clase. La cláusula que faculta la exhumación de los restos establece que: "las partes acuerdan que si el comprador o propietario no pagare dos cuotas de mantención consecutivas, el vendedor podrá declarar resuelto ipso facto el contrato, incurriendo además en una multa, a título de avaluación anticipada de perjuicios equivalente al 100 por ciento del monto pagado a fecha de adquisición de la sepultura. El vendedor podrá tomar posesión de la respectiva sepultura, una vez transcurridos 30 días después de la expedición de carta certificada, quedando expresamente facultado para solicitar la exhumación de los restos que se encontraren sepultados".
} 
construirá lo que diga su capacidad económica (considerando $16^{\circ}$ ). De este modo, no resultaría tan extraño e ilógico, más bien sería -en sus palabras"coherente y racional", según la finalidad del contrato, que se prevea en el contrato la regulación de los costos de mantención. Dicho costo asume la naturaleza de un cargo fijo que se actualiza conforme a la UF (considerando $19^{\circ}$ y $\left.20^{\circ}\right)$.

Así, se reafirma un criterio primordial que justifica la adaptación del contrato: deberían considerarse lícitas (no arbitrarias) aquellas cláusulas de modificación unilateral que empleen criterios racionales y objetivos que atiendan a la finalidad del contrato.

ii. Servicios de tiempos compartidos. En Camus con Comercializadora con Aldo Manatagua S.A., ${ }^{82}$ se reclamó la falta de entrega del reglamento del plan vacacional protocolizado en una Notaría de Santiago. En ella se incluían ciertas cláusulas que permitían cobrar un pago adicional por el uso del sistema, pactos comisorios, cuotas de mantención de servicios. Sin mayores fundamentos se declararon abusivos por desequilibrar los derechos de las partes y por estar "casi ocultos" para los consumidores.

Por último, en Fuentes con Thermas Internacional S.A., ${ }^{83}$ se ventiló la misma cuestión. Es decir, si la cuota de mantención consignada en un Reglamento que, además no fue entregado al consumidor, formaba parte del contrato por adhesión. Se consideró que el cobro de la cuota de mantención, aun cuando liberaba el pago por 10 años, sí era abusiva bajo la regla del artículo 16 literal b) que prohíbe las estipulaciones que establecen un incremento de precios y la letra g) por atentar contra la buena fe.

Con estos fallos aparece un criterio accesorio o de forma, si se quiere, que condiciona la ilicitud de las cláusulas. Es arbitrario ocultar las modificaciones unilaterales predispuestas por el proveedor.

\section{CONCLUSIONES}

A lo largo de estas páginas se han visto algunos criterios que permiten modelar la licitud o ilicitud de las facultades unilaterales del proveedor en la contratación masiva con consumidores.

\footnotetext{
${ }^{82}$ Corte de Apelaciones de Santiago, 21 de septiembre de 2007, Rol No 3746-2007.

${ }^{83}$ Corte de Apelaciones de Santiago, 21 de julio de 2010, Rol No 927-2010.
} 
De este modo, un primer estándar que permite definir la arbitrariedad será la existencia de un perjuicio económico para el consumidor. Este criterio fue empleado en el ámbito de la televisión por cable, cambios de jornadas educacionales, espectáculos públicos, servicios de salud, servicios aéreos, deportivos, funerarios y tiempos compartidos.

Es arbitrario suprimir parte de la prestación ofrecida al consumidor para exigir el pago de un precio adicional por ella.

Asimismo, debe sancionarse la cláusula que permite al proveedor realizar cualquier clase de alteración de la prestación. En este caso, la arbitrariedad se manifiesta en una falta de certeza e incertidumbre para los consumidores.

También resulta arbitrario alzar el precio, sin obtener mayores prestaciones. Incluso, si no hay justificaciones reales que toleren esa alza de precio, ni mejoras en el plan contratado o mayores beneficios para los consumidores.

Bajo la órbita de las expectativas razonables no se podría alzar el precio, ni los montos de las cuotas de forma unilateral. Tampoco se pueden ocultar las modificaciones unilaterales.

De este modo, se aprecia cómo la abusividad se relaciona con la finalidad del contrato. Por ello, si no se presta el servicio no puede cobrarse.

En definitiva, la modificación unilateral y arbitraria se manifiesta en la forma de un perjuicio para el consumidor, el enriquecimiento sin causa y la restricción para disponer de forma libre de sus derechos.

Por otra parte, una cláusula que permite la adaptación o modificación de la prestación no debe ser general y vaga, porque dejaría al arbitrio las decisiones contractuales. Precisamente, por esta razón se critica la aceptación del "desarrollo del negocio", que peca de ambigüedad y lesiona los derechos del consumidor.

En fin, deberían estimarse lícitas aquellas cláusulas de modificación unilateral que empleen criterios racionales y objetivos que atiendan a la finalidad del contrato.

\section{BIBLIOGRAFÍA}

Abeliuk Manasevich, René, Las obligaciones, Thomson Reuters, Santiago, 2014, 6ta edic. actualizada, T. II.

Barrientos Camus, Francisca, "Silencio y aceptación tácita. Aumento 
unilateral. Prescripción", Revista chilena de Derecho Privado, 2013, N²0, pp. 255-261.

Barrientos Camus, Francisca, "Una mirada al silencio y la aceptación en los contratos por adhesión con consumidores a partir del caso CENCOSUD”, en: Barrientos F. (coord.), Condiciones generales de la contratación y cláusulas abusivas, Cuadernos de Análisis Jurídicos. Colección de derecho privado VIII, Ediciones Universidad Diego Portales, Santiago, 2014, pp. 29-48.

Barrientos Camus, Francisca, "La modificación unilateral en los contratos de salud y televisión por cable. Criterios judiciales”, en: Departamento de Derecho Privado Universidad de Concepción (edit.). Barría M. (coord.), Estudios de derecho civil XI, Thomson Reuters, Santiago, 2015, pp. 451-465.

CAPrile Biermann, Bruno, "El desistimiento unilateral o renuncia: una especial forma de extinción de los contratos", en: Figueroa, G.; Barros, E.; Tapia, M. (coords.), Estudios de Derecho Civil VI, Editorial Abeledo Perrot Legal Publishing, Santiago, 2011, pp. 271-296.

Castelblanco Koch, Mauricio, Las obligaciones restitutorias del Código Civil y la inflación, Editorial Jurídica de Chile, Santiago, 1979.

Cea Egaña, José Luis, Derecho Constitucional chileno, Ediciones UC, Santiago, 2012, II.

Claro Solar, Luis, Explicaciones de Derecho Civil chileno y comparado. De las obligaciones III, Editorial Jurídica de Chile, Santiago, reimpr. 2013, T. XII .

Diez Picazo, Luis, Fundamentos de Derecho Civil Patrimonial I. Introducción a la teoría del contrato, Thomson Reuters, Madrid, 2007, 6ta edic.

De la MAZA, Íñigo, “¿Llegar y llevar? Una mirada al crédito de las casas comerciales", Revista de Derecho (Valdivia), 2007, Vol. XX N 1, pp. 271-296.

De la MazA, Íñigo, “¿Pero qué es lo que esperabas? Contratos por adhesión y expectativas razonables”, en: Turner, S.; Varas, J.A. (coords.), Estudios de Derecho Civil IX, Legal Publishing - Thomson Reuters, Santiago, 2014, pp. 333-350.

Durany Pinch, Salvador, “Artículos 5 y 7”, Menéndez A. y Díez Picazo L. (dirs.) y Alfaro Águila-Real J. (coord.), Comentarios a la Ley sobre Condiciones Generales de la Contratación, Civitas, Madrid, 2002, pp. 264-335.

IsLer Soto, Erika, "La causal de abusividad establecida en el artículo 16 letra a) de la LPDC", en: Barrientos, F. (coord.), Condiciones generales de la contratación y cláusulas abusivas, Cuadernos de Análisis Jurídicos. Colección de derecho privado VIII, Ediciones Universidad Diego Portales, Santiago, 2014, pp. 145-172. 
Momberg Uribe, Rodrigo, "Primera Sala de la Corte Suprema, 24 de abril de 2013, Rol 12.355-11, Revista chilena de Derecho Privado, 2013, No 20, pp. 245-253.

Momberg Uribe, Rodrigo, "Las cláusulas de modificación unilateral en los contratos de consumo", en: Barrientos, F. (coord.), Condiciones generales de la contratación y cláusulas abusivas, Cuadernos de Análisis Jurídicos. Colección de derecho privado VIII, Ediciones Universidad Diego Portales, Santiago, 2014, pp. 173-190.

Nogueira Alcalá, Humberto, Derechos fundamentales y garantías constitucionales, Editorial Librotecnia, Santiago, 2013, 4ta edic. actualizada, T. I.

Pinochet Cantwell, Francisco José, El recurso de protección, Editorial El Jurista, Santiago, 2016.

Pinochet Olave, Ruperto, "La voluntad y el silencio en los contratos de adhesión el que calla no otorga. Una revisión a propósito de la sentencia de la Excma. Corte Suprema de 24 de abril de 2013 recaída en el caso Sernac con Cencosud", en: Turner, S.; Varas, J.A. (coords.), Estudios de Derecho Civil IX, Legal Publishing-Thomson Reuters, Santiago, 2014, pp. 427-442.

Pizarro Wilson, Carlos "La ley debe regular los actos que valgan aceptación de ofertas de modificación”, en: Barrientos, F. (coord.), Condiciones generales de la contratación y cláusulas abusivas, Cuadernos de Análisis Jurídicos. Colección de derecho privado VIII, Ediciones Universidad Diego Portales, Santiago, 2014, pp. 19-28.

Pizarro Wilson, Carlos; Petit Pino, Jean, "Comentarios al artículo 16 a”, en: de la Maza Í. y Pizarro C. (directores), Barrientos, F. (coord.), La protección de los derechos de los consumidores, Editorial Thomson Reuters, Santiago, 2013, pp. 305-311.

Ríos LabBé, Sebastián, "El papel del unilateralismo en el derecho de los contratos”, Schopf, A. y Marín, J.C. (editores), Lo público y lo privado en el derecho, Thomson Reuters, Santiago, 2017, pp. 641-654.

Rozas Zambrano, Marco, "Posibilidad de dejar sin efecto el contrato en la ley del consumidor", en: Barrientos, F. (coord.), Condiciones generales de la contratación y cláusulas abusivas, Cuadernos de Análisis Jurídicos. Colección de derecho privado VIII, Ediciones Universidad Diego Portales, Santiago, 2014, pp. 243-258.

Ruz LÁrtiga, Gonzalo, Nuevo Derecho Concursal chileno. Procedimientos concursales de empresas y personas deudoras, Thomson Reuters, Santiago, 2017. 
Tapia Rodríguez, Mauricio, "Silencio y aceptación del consumidor", en: Turner, S. y Varas, J.A. (coords.), Estudios de Derecho Civil IX, Legal Publishing-Thomson Reuters, Santiago, 2014, pp. 443-462.

Tapia Rodríguez, Mauricio; Valdivia Olivares, José Miguel, Contrato por adhesión. Ley $N^{\circ} 19.496$, Editorial Jurídica de Chile, Santiago, 2002.

\section{SENTENCIAS CITADAS}

- Álvarez, SERNAC con Terra Networks: Corte de Apelaciones de Santiago, 12 de enero de 2005, Rol No 3759-2003.

- Álvarez con Universidad Finis Terrae: Tercer Juzgado de Policía Local de Providencia, 15 de diciembre de 2006, Rol No 7997-4-2006.

- Aravena, SERNAC con Telefónica Móvil: Primer Juzgado de Policía Local de Santiago, 17 de octubre de 2005, Rol No 14.323-2002.

- Barrientos con Universidad de Arte y Ciencias Sociales ARCIS: Corte de Apelaciones de Santiago, 4 de noviembre de 2009, Rol No 10.892-2009.

- Bezanilla, SERNAC con VTR: Corte Suprema, 18 de mayo de 2009, Rol N 1672-09.

- Bustamante, SERNAC con Telefónica Móvil: Primer Juzgado de Policía Local de Santiago, 20 de octubre de 2005, Rol No 12.004-2002.

- Camus con Comercializadora con Aldo Manatagua S.A.: Corte de Apelaciones de Santiago, 21 de septiembre de 2007, Rol No 3746-2007, Legal Publishing 37182.

- Canales, SERNAC con Telefónica Móvil: Primer Juzgado de Policía Local de Santiago, 30 de enero de 2006, Rol No 19.583-2003.

- Contreras con Centro de formación técnica Salesiano don Bosco: Primer Juzgado de Policía Local de Puerto Montt, 19 de enero de 2005, Rol No 288604.

- Contreras con Hospital Clínico de la Universidad de Chile: Corte Suprema, 6 de enero de 2012, Rol No 8.905-2011

- Cuevas, SERNAC con Telefónica Móvil: Primer Juzgado de Policía Local de Santiago, 17 de octubre de 2005, Rol No 12.001-2002.

- Fernández con Banmédica S.A: Corte Suprema, 14 de enero de 2010, Rol No 9029-09.

- Fernández, SERNAC con Telefónica Móvil: Primer Juzgado de Policía Local de Santiago, 30 de enero de 2006, Rol No 12.712-2002. 
- Finch, SERNAC con Telefónica Móvil: Primer Juzgado de Policía Local de Santiago, 27 de diciembre de 2005, Rol N $12.712-2002$.

- Fuentes con Thermas Internacional S.A.: Cuarta Sala de la Corte de Apelaciones de Santiago, 21 de julio de 2010, Rol No 927-2010.

- Leñero, SERNAC con Telefónica Móvil: Primer Juzgado de Policía Local de Santiago, 10 de mayo de 2006, Rol No 10.909-2002.

- Herrera, SERNAC con Telefónica Móvil: Primer Juzgado de Policía Local de Santiago, 27 de diciembre de 2005, Rol No 12.712-2002.

- Jarpa con LAN: Segundo Juzgado de Policía Local de Las Condes, 18 de enero de 2010, Rol No 73.645-5-2009.

- Hubner y otro con Universidad Mayor: Corte de Apelaciones de Santiago, 01 de julio de 2008, Rol No 8775-2004, Legal Publishing No 39241.

- Livacic con Cementerio Parque de Rengo: Juzgado de Policía Local de Rengo, 14 de marzo de 2007, Rol No 173.969.

- Llefi Llefi y otros con Administradora de Parques Dobro Ltda.: Corte de Apelaciones de Valdivia, 01 de marzo de 2012, Rol: 237-2011, Cita online: CL/JUR/1108/2012; 59112.

- Lobo, SERNAC con VTR: Corte Suprema, 18 de noviembre de 2008, Rol No 3528-08.

- Manríquez, SERNAC con Telefónica Móvil: Primer Juzgado de Policía Local de Santiago, 20 de febrero de 2006, Rol No 183-2004.

- Molina, SERNAC con Telefónica Móvil: Primer Juzgado de Policía Local de Santiago, 20 de enero de 2006, Rol No 9970-2002.

- No se consignan partes: Corte de Apelaciones de Antofagasta, 02 de noviembre de 2005, Rol No 122-2005.

- Parra con Universidad Andrés Bello: Corte de Apelaciones de Santiago, 05 de julio de 2008, Rol No 2335-2008.

- Peña y otros, SERNAC con Cementerio Parque Santiago (El retiro inmobiliaria e inversiones S.A.): Corte de Apelaciones de Santiago, 18 de julio de 2007, Rol No 3040-2007.

- Repol, SERNAC con Telefónica Móvil: Primer Juzgado de Policía Local de Santiago, 27 de diciembre de 2005, Rol No 10.580-2002.

- Rivera, SERNAC con Telefónica Móvil: Primer Juzgado de Policía Local de Santiago, 27 de diciembre de 2005, Rol No 5.890-2003.

- Salas, SERNAC con Universidad Pedro de Valdivia: Corte de Apelaciones de Santiago, 13 de agosto de 2008, Rol No 4192-2008.

- Sánchez con Universidad del Mar: Segundo Juzgado de Policía Local de 
Copiapó, 27 de noviembre de 2007, Rol No 3296-2007.

- Servicio Nacional del Consumidor con Créditos Organización y Finanzas S.A.: Corte Suprema, 8 de octubre de 2015, Rol N 27802-2014.

- Servicio Nacional del Consumidor con Ticketmaster: Corte de Apelaciones de Santiago, 11 de noviembre de 2014, Rol No 4.835-2014.

- Servicio Nacional del Consumidor con Gimnasios Pacific Fitness Chile Ltda.: Corte de Apelaciones de Santiago, 11 de mayo de 2015, Rol Nº1693-2015. - Ureta, SERNAC y La Administradora del Prado y La Foresta S.A.: Corte de Apelaciones de San Miguel, 13 de agosto de 2007, Rol No 484-2007.

- Villar con Ticketmaster: Corte de Apelaciones de Santiago, 30 de septiembre de 2009, Rol No 10126-2009. 